\section{Use of a Heimlich flutter valve for pneumothorax in cystic fibrosis}

\author{
F P Edenborough, I Hussain, \\ D E Stableforth
}

\begin{abstract}
The use of a Heimlich flutter valve in an adult patient with cystic fibrosis with hypercapnic respiratory failure which allowed resolution of a persisting pneumothorax after failure of conventional tube drainage is reported. The patient was managed at home and avoided surgical pleurodesis which could have jeopardised transplantation at a later date.
\end{abstract}

(Thorax 1994;49:1178-1179)

\section{Case report}

The 24 year old woman with cystic fibrosis was an insulin dependent diabetic with a past history of nasal polypectomy, cholecystectomy, duodenal ulceration, and paroxysmal supraventricular tachycardia. She had been chronically colonised with Pseudomonas cepacia for approximately 12 months and her lung function was $\mathrm{FEV}_{1} / \mathrm{FVC} \quad 0.55 / 1.01 \quad(20 \% / 32 \%$ predicted) with a $\mathrm{PaCO}_{2}$ of $6.9 \mathrm{kPa}$ and $\mathrm{PaO}_{2}$ of $6.0 \mathrm{kPa}$ breathing air. She had already had bilateral pneumothoraces, the right side requiring tube drainage in 1989, the left resolving spontaneously.

She presented in January 1992 with a small right apical pneumothorax, initially thought not to require tube drainage. She was commenced on antibiotics but by the tenth day repeat radiography showed the pneumothorax to have enlarged significantly. A drain was placed in the fifth intercostal space in the mid-axillary line. The pneumothorax resolved and the drain was removed seven days later.

During the next month a Portacath was inserted on the left side to facilitate venous access and a percutaneous gastrostomy was sited, both without complications. Chest radiographs performed after each procedure showed no evidence of pneumothorax.

Four months later she developed a left pneumothorax requiring five days of drainage via a tube in the left fifth intercostal space in the mid-axillary line. Ten days after discharge she had a further large left pneumothorax and another drain was placed in the fourth intercostal space in the mid-axillary line. Six days later suction was commenced but after five days this drain continued to bubble and, in an attempt to avoid surgery, it was removed. A further drain was inserted in the sixth intercostal space in the mid-axillary line. Despite this there was no resolution and a Heimlich flutter valve was attached to the drain 19 days after admission to facilitate mobility and she was discharged. The drain was removed after 63 days when the lung was fully inflated. She was discharged with an $\mathrm{FEV}_{1} / \mathrm{FVC}$ of $0 \cdot 49 / 1 \cdot 03$. Except for minor surgical emphysema there were no complications. There has been no recurrence of pneumothorax 14 months later.

\section{Discussion}

Experience of 205 patients with cystic fibrosis with 395 episodes of pneumothorax has been reviewed. ${ }^{1-3}$ Pneumothoraces occur a little more frequently in men and may occur at any age. Patients are often ill with $\mathrm{FEV}_{1}<50 \%$ predicted, low body weight, and have chronic colonisation of the lungs of Pseudomonas aeruginosa. Pneumothorax recurs in $50-83 \%$ of cases. Management has included observation, chemical sclerosants (tetracycline, silver nitrate, quinacrine), thoracocentesis, thoracoscopy and talc poudrage or pleural abrasion, open thoracotomy and partial pleurectomy, segmentectomy or bullectomy. Penketh et al suggested that a persisting air leak at seven days is usually an indication for surgical intervention, but more recent opinion ${ }^{4}$ suggests that this should be avoided if possible in patients with cystic fibrosis. An exception to this may be thoracoscopic stapling, with or without pleurodesis, which is safer and less painful than thoracotomy ${ }^{3}$ and may find favour in the treatment of pneumothorax in those patients who could tolerate anaesthesia.

Our patient was unfit for anaesthesia. Although prolonged intercostal drainage $(>7$ days) has been associated with a high morbidity and immediate and delayed mortality, ${ }^{2}$ no study has reported the use of the Heimlich flutter valve in patients with cystic fibrosis. The valve was first described in $1965^{6}$ and has become increasingly popular in outpatient management with both large ${ }^{7}$ and small $^{8}$ calibre tubes. No major complications have been reported except accidental dislodgement and inadvertent reattachment back to front, when they may induce tension pneumothorax. ${ }^{9}$ This can be prevented by secure taping of the union between drain and valve. Blockage and infection are theoretical problems but have not been reported.

We believe this to be the first reported use of a Heimlich flutter valve to manage a persisting pneumothorax in a patient with cystic fibrosis. The technique allowed resolution of the leak at home in a patient in hypercapnic respiratory failure with poor lung function in whom surgery might have been life threatening and which could have jeopardised transplantation at a later date.

1 Schuster SR, McLaughlin FJ, Matthews WJ, Strieder DJ, Khaw KT, Schwachman H. Management of pneumothorax in cystic fibrosis. $\mathcal{F}$ Pediatr Surg 1983;18:492-7. 
2 Penketh A, Knight RK, Hodson ME, Batten JC. Management of pneumothorax in adults with cystic fibrosis. Thorax 1982 ; 37:850-3.

3 Spector ML, Stern RC. Pneumothorax in cystic fibrosis: a 26 year experience. Ann Thorac Surg 1989;47:204-7.

4 Hodson ME. Cystic fibrosis in adults. In: Brewis RAL, Gibson GJ, Geddes DM, eds. Respiratory medicine. London: Bailliere Tindall, 1990:783.

5 Hazelrigg SR, Landreneau RJ, Mack M, Acuff T, Seifert PE, Auer JE, et al. M. Thoracoscopic stapled resection for spontaneous pneumothorax. F Thorac Cardiovasc Surg 1993; 105:389-93.
6 Heimlich HJ. Heimlich flutter valve: effective replacement for drainage bottle. Hospital Topics 1965;43:122-3.

7 Mercier C, Page A, Verdant A, Cossette R, Dontigny L, Pelletier LC. Outpatient management of intercostal tube drainage of spontaneous pneumothorax. Ann Thorac Surg 1976;22:163-5

8 Minami H, Saka H, Senda K, Horio Y, Iwahara T, Nomura $\mathrm{F}$, et al. Small caliber catheter drainage for spontaneous pneumothorax. Am f Med Sci 1992;304:345-7.

9 Mainini SE, Johnson FE. Tension pneumothorax complicating small-caliber chest tube insertion. Chest 1990;97: $759-60$

Thorax 1994;49:1179-1180

\section{Empyema and mediastinitis complicating retropharyngeal abscess}

Masazumi Watanabe, Yoshiro Ohshika, Teruhiro Aoki, Keigo Takagi, Susumu Tanaka, Toshiro Ogata

\begin{abstract}
A 21 year old man with a retropharyngeal abscess complained of right sided chest pain, and chest radiography and thoracocentesis revealed an empyema. A computed tomographic scan of the chest showed a posterior mediastinal abscess communicating with the right pleural cavity. Emergency thoracotomy was performed and the mediastinal abscess and empyema were drained.
\end{abstract}

(Thorax 1994;49:1179-1180)

Acute empyema following a retropharyngeal abscess and mediastinitis in an adult is very rare and often fatal. ${ }^{12}$ This report presents a case that was cured with surgical intervention.

\section{Case report}

A 21 year old man was admitted with a high fever to our hospital complaining of dysphagia and a four day history of a sore throat for which he was given oral antibiotics. On admission physical examination disclosed diffuse erythema and swelling of the pharynx and swelling and tenderness of the right side of the neck, but cervical lymph adenopathy was not present. There were no abnormal dental findings and the tonsils appeared normal. A chest radiograph showed widening of the upper mediastinum, and radiography of the soft tissues of the neck showed retropharyngeal gas and widening of the retropharyngeal space. A transoral retropharyngeal tap was performed and pus was obtained consistent with a retropharyngeal abscess. Cultures grew $\alpha$-streptococcus, $\beta$-streptococcus and staphylococcus. His white cell count was $13100 / \mathrm{mm}^{3}$ and the serum level of Creactive protein (CRP), a non-specific marker for acute inflammation, was $37 \cdot 8 \mathrm{mg} / \mathrm{dl}$.
Treatment was started with intravenous cefmetazole to which these organisms proved sensitive. The following day he developed right sided chest pain and radiographs showed a right pleural effusion. Pus was obtained during thoracocentesis and a chest tube was inserted immediately. The pleural effusion grew the same microorganisms as the retropharyngeal pus and the patient's mediastinitis appeared consequent to the retropharyngeal abscess which had perforated into the pleural cavity. An oesophagogram was normal. The patient's condition rapidly improved, temperature became normal, and both the pharyngeal and cervical swelling improved, but a computed tomographic scan of the chest on the fifth hospital day showed an increasing encapsulated mediastinal abscess between the oesophagus and vertebral bodies (fig 1). Since the mediastinal abscess had not been drained adequately a right thoracotomy was performed on the seventh hospital day, and $200 \mathrm{ml}$ of turbid, yellow-white fluid obtained. The upper mediastinal pleura appeared swollen between the superior vena cava and vertebral

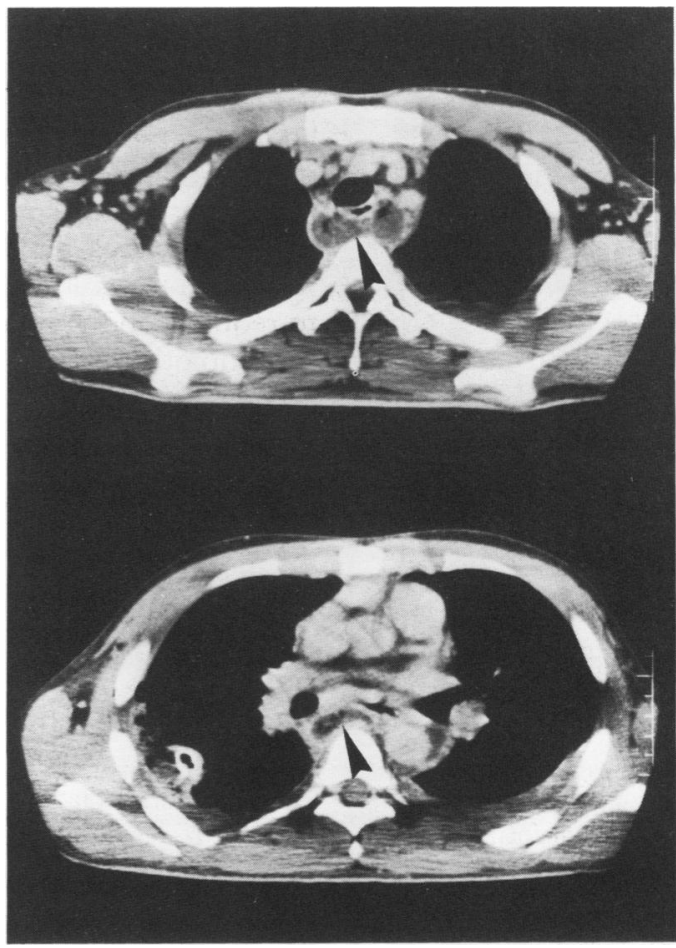

Figure 1 Computed tomographic scan of the chest. Arrow heads point to the encapsulated posterior mediastinal abscess between the oesophagus and the vertebral bodies. A chest tube was already inserted in the right pleural cavity. 